\title{
A Clinical Study - Resection and Anastomosis of Bowel in Our Surgical Practice
}

\author{
Raghunandan $\mathbf{R}$ \\ Assistant Professor, Department of Surgery, Kamineni Institute of Medical Sciences, Hyderabad, Telangana, India.
}

\section{Abstract}

Background: Anastomotic leaks are among the most dreaded complications after bowel surgery. In the present era, even with better understanding of the impact of local and systemic factors on anastomotic healing, dehiscence and leakage remains frequent and serious problem associated with high morbidity and mortality. However, problems with definitions and the retrospective nature of previous analyses have been major limitations. The aim of the study to use a prospective database to study the incidence of intestinal resection and anastomoses, to determine important factors and their significance in the healing of the anastomosis along with identifying the most ideal suture material for these techniques in our practice. Subjects and Methods: This study was carried out on 40 patients who underwent resection and anastomosis of bowel for various pathological causes in Kamineni Institute of Medical Sciences \& Hospital Hyderabad during September 2018 to September 2019. Results: Out of the 40 patients who underwent resection and anastomosis of bowel, Anastomotic leaks were observed in 10 (25\%) cases and all of them belonged to the group who were operated on emergency basis. Hypoproteinaemia, peritonitis and perioperative blood transfusions, hypovolemia were important attributable factors identified in the leak group. Minimal leaks were observed in the group of patients who were anastomosed with vicryl suture material alone. Mortality was observed in 3patients in the leak group. At 6 month follow up none of them developed anastomosis related complications like stenosis, diverticulum. Conclusion: The present study shows majority of the patients undergoing resection and anastomosis were dealt on an emergency basis. Multivariate analysis showed six predictive variables i.e., serum albumin less than $3 \mathrm{~g} / \mathrm{l}$, use of corticosteroids, bacterial peritonitis, malignancy, COPD, perioperative blood transfusions had a higher risk of developing anastomotic leaks. Vicryl when used alone being the suture material of choice.

Keywords: Resection and anastomosis of bowel, leaks, intestinal healing, fecal fistula

Corresponding Author: Raghunandan R, Assistant Professor, Department of Surgery, Kamineni Institute of Medical Sciences, Hyderabad, Telangana, India.

E-mail: meryrapo@gmail.com

Received: 23 December 2019

Revised: 27 January 2020

Accepted: 5 February 2020

Published: 26 May 2020

\section{Introduction}

The creation of a join between two bowel ends is an operative procedure that is of central importance in the practice of a general surgeon and is still by far the most common surgical procedure, especially in the emergency setting, and is also commonly performed in the elective setting when resections are carried out for benign or malignant lesions of the gastrointestinal tract, done by the present day General Surgeon. This procedure restores intestinal continuity after removal of a pathological condition affecting the bowel. A disastrous complication of intestinal anastomosis is anastomotic leak resulting in peritonitis, which is associated with high morbidity and mortality. ${ }^{[1-3]}$ Proper surgical technique and adherence to fundamental principles is imperative to ensure successful outcome after intestinal anastomosis.
Safety in gastrointestinal surgery may thus depend to a large extent on the technical expertise of the operating surgeon in his performance of the intestinal anastomosis. This expertise is acquired with practice as is any other skillful art but a gastrointestinal operation involves a series of exercises in surgical judgment and it is imperative to adhere to several wellestablished principles. The main ones relate to the creation of a tension-free join with good apposition of the bowel edges in the presence of an excellent blood supply. The importance of surgical technique is underscored by the wide variations of anastomotic leakage rates among surgeons and it is only by attention to many details that safety is achieved in such surgery. ${ }^{[4-7]}$

Knowledge of gastrointestinal (GI) surgery has developed gradually over the centuries from a mystical to a scientific level today. During this evolution much emphasis has been placed 
on suture materials and methods without much understanding of the healing process itself.

Nevertheless, anastomotic leakage and dehiscence remain frequent and serious problems associated with high morbidity and mortality. Because it is difficult to examine the mechanisms of gastrointestinal healing in clinical models except by retrospective analysis, studying animal models, with their accepted limitations, has learned much. ${ }^{[8,9]}$

Here, I have made an attempt to study the Incidence of Intestinal Resection and Anastomosis in $\mathrm{CG} \& \mathrm{BH}$ its various etiologies with factors determining healing of an anastomosis. Various techniques used in the sutured anastomosis of the intestine among our surgeons and determine the technique which is best and has the least anastomotic leaks, finally to study the factors which have a bearing on the safe healing of the intestinal anastomosis among all the patients undergoing intestinal resections and Anastomosis for various causes in the Department of General Surgery.

\section{Aims \& Objectives:}

1. Incidence of intestinal resections and Anastomosis in Tertiary care hospital and various causes leading to it.

2. To study important factors which determine the healing of gastrointestinal tract after an Anastomosis and verify their significance in healing of anastomosis.

3. To study various suture methods (sutures/staples) used for anastomoses at different anatomical locations and thus determine the most ideal suture material for these techniques in our study.

\section{Subjects and Methods}

This study involved 40 patients between September 2018 and September 2019 undergoing intestinal resection and subsequent anastomoses for various causes in the Departments of General surgery at Kamineni Institute of Medical Sciences, Narketpally, Hyderabad.

\section{Inclusion criteria}

- All the patients undergoing intestinal resections for various causes requiring an anastomosis for distal continuity of bowel.

\section{Exclusion criteria}

- All the gastro intestinal anastomoses.

- All the biliary and enteric anastomoses/ pancreatico-enteric anastomoses.

- Patients with malignancy who have undergone pre-operative radiotherapy and chemotherapy.

- Steroid dependent patients.

\section{Methods for collection of Data}

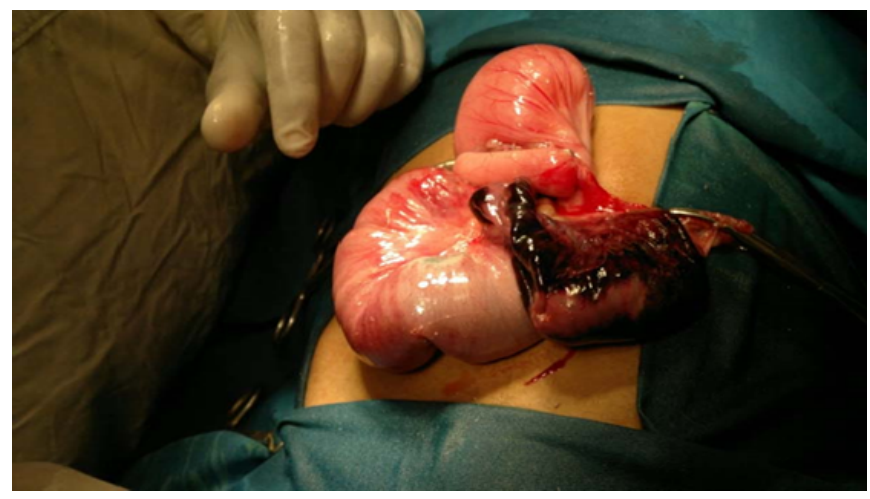

Figure 1: Gangrenous bowel intussusception

- Direct interview with patient and obtaining detailed history.

- Thorough clinical examination

- A pretested structural proforma will be used to collect relevant information for each individual patients selected.

- Cases will be selected consequently based on inclusion and exclusion criteria.

- Appropriate investigations performed over the patients.

- Routine investigations: Blood-Complete hemogram, RBS, B.Urea, S.Creatinine, HIV, HBsAg.

- Relevant: Radiological - X ray abdomen, ultra sound of abdomen, CT scan abdomen.

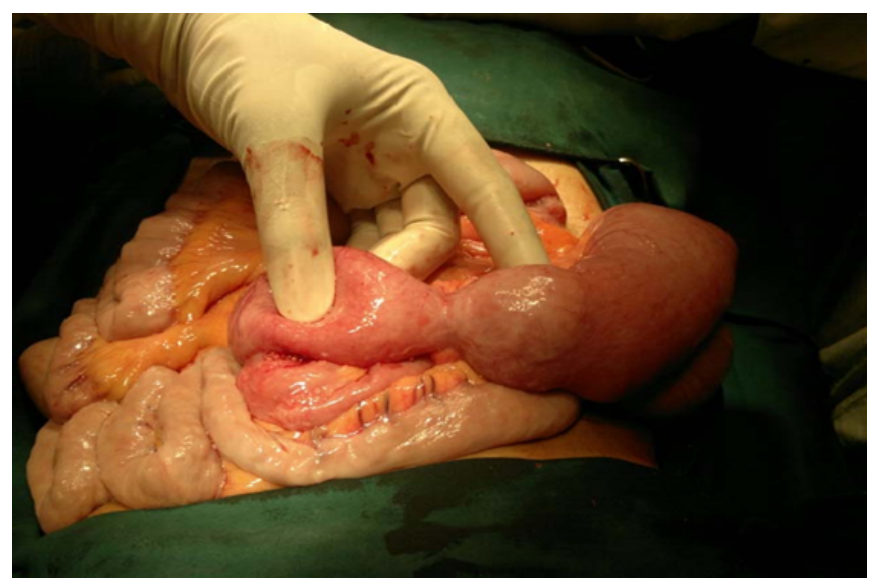

Figure 2: Ileal stricture

\section{Results}

The total number of cases considered in this study were 40 . These cases were considered for the study using the inclusion and exclusion criteria as mentioned above. Out of the 240 
laparotomies for various causes during the study period 40 of them were done for resection and anastomoses of intestine.

In the present study there were $22(55 \%)$ male patients and 18 $(45 \%)$ female patients. The male to female ration around 1.5:1

\section{Table 1: Sex Incidence}

\begin{tabular}{|l|l|l|}
\hline Sex & Number & Percentage (\%) \\
\hline Male & 22 & 55 \\
\hline Female & 18 & 45 \\
\hline
\end{tabular}

In the present study patients below 15 years were $4(10 \%)$,in the age group 16-30 yrs were $7(17.5 \%)$, in the age group 31$45 \mathrm{yrs}$ were $15(37.5 \%)$, in the age group 46-60 yrs were 4 $(10 \%)$, the age group 61 \&above considered old age were 10 $(25 \%)$.

In the present study, $10(25 \%)$ out of 40 patients underwent intestinal resection and anastomoses for malignant conditions. Out of which ca rectum $2(20 \%)$, ca colon $3(30 \%)$, casigmoid $3(30 \%)$, ca caecum $2(20 \%)$.

\begin{tabular}{lll}
\hline \multicolumn{2}{l}{ Table 2: Age distribution } & \\
\hline Age & Number & Percentage (\%) \\
$<15$ & 4 & 10 \\
$16-30$ & 7 & 17.5 \\
$31-45$ & 15 & 37.5 \\
$46-60$ & 4 & 10 \\
$>61$ & 10 & 25 \\
\hline
\end{tabular}

Table 3: Types of Malignancy $(\mathrm{N}=10)$

\begin{tabular}{lll}
\hline $\begin{array}{l}\text { Malignancy } \\
\text { Type }\end{array}$ & Number & Percentage (\%) \\
Rectum & 2 & 20 \\
Cocolon & 3 & 30 \\
Casigmoid & 3 & 30 \\
Cacaecum & 2 & 20 \\
\hline
\end{tabular}

In the present study, $16(36 \%)$ out of 40 patients underwent intestinal resection and Anastomoses for intestinal obstruction. Out of which $6(37.5 \%)$ patients for post-operative adhesions with intestinal gangrene, $2(12.5 \%)$ patients for intussusceptions, $2(12.5 \%)$ patients for sigmoid volvulus, 2 (12.5\%) patients for ileal stricture, $2(12.5 \%)$ patients for bands and 2 $(12.5 \%)$ patients for terminal ileal knot.

In the present study 4 out of 40 cases underwent Intestinal Resection and Anastomoses for Abdominal Koch's. Out of which $3(75 \%)$ cases were for Ileo- caecal Koch's and 1 (25\%) for $\mathrm{Tb}$ hepatic flexure.

\begin{tabular}{|c|c|c|}
\hline $\begin{array}{l}\text { Intestinal obstruc- } \\
\text { tion }\end{array}$ & Number & Percentage (\%) \\
\hline Intestinal gangrene & 6 & 37.5 \\
\hline Intussusceptions, & 2 & 12.5 \\
\hline Sigmoid volvulus & 2 & 12.5 \\
\hline ileal stricture & 2 & 12.5 \\
\hline bands & 2 & 12.5 \\
\hline Ileal Knot & 2 & 12.5 \\
\hline
\end{tabular}

Table 5: Abdominal Tuberculosis $(\mathrm{N}=4)$

\begin{tabular}{|c|c|c|}
\hline $\begin{array}{l}\text { Abdominal Tuber- } \\
\text { culosis }\end{array}$ & Number & Percentage (\%) \\
\hline Abdominal Koch's & 3 & 75 \\
\hline Ileo-caecal Koch's & 1 & 25 \\
\hline
\end{tabular}

In the present study 4 out of 40 cases underwent Intestinal Resection and Anastomoses for Strangulated Hernia Amongst which $2(50 \%)$ strangulated Inguinal hernia and $2(50 \%)$ were for strangulated recurrent incisional hernia.

\begin{tabular}{|c|c|c|}
\hline Strangulated Hernia & Number & $\begin{array}{l}\text { Percentage } \\
(\%)\end{array}$ \\
\hline $\begin{array}{l}\text { strangulated Inguinal } \\
\text { hernia }\end{array}$ & 2 & 50 \\
\hline $\begin{array}{l}\text { strangulated recurrent } \\
\text { incisional hernia. }\end{array}$ & 2 & 50 \\
\hline
\end{tabular}

In the present study 4 out of 40 cases underwent Intestinal Resection and Anastomoses for Enteric fever Related condition. And all 4 cases were for ileal perforation with peritonitis.

\begin{tabular}{|c|c|c|}
\hline Entric fever pathology & Number & $\begin{array}{l}\text { Percentage } \\
(\%)\end{array}$ \\
\hline $\begin{array}{l}\text { ileal perforation with } \\
\text { peritonitis }\end{array}$ & 4 & $100 \%$ \\
\hline Jejunal perforation & 0 & $\%$ \\
\hline
\end{tabular}

In the present study 4 out of 40 cases underwent Intestinal Resection and Anastomoses for Mesentric Ischaemia, 2 out of 40 cases for blunt and penetrating Trauma abdomen (1 each respectively) 1 each out of 40 cases for Inflammatory bowel disease and Hirschsprung Disease, 2 out of 50 cases for Meckel's Diverticulum.

Thus the various Etiologies leading to Intestinal Resection and Anastomoses is summarized and represented in the following 


\begin{tabular}{|lll|}
\hline Table 8: Etiologies of Resection and Anastomoses \\
\hline $\begin{array}{l}\text { Etiology of Resection and } \\
\text { anastomoses }\end{array}$ & Number & $\begin{array}{l}\text { Percentage } \\
\text { (\%) }\end{array}$ \\
\hline Mesentric Ischaemia & 4 & $10 \%$ \\
\hline Blunt trauma & 1 & $2.5 \%$ \\
\hline penetrating Trauma abdomen & 1 & $2.5 \%$ \\
\hline Inflammatory bowel disease & 1 & $2.5 \%$ \\
\hline Hirschsprung Disease & 1 & $2.5 \%$ \\
\hline Meckel's Diverticulum. & 2 & $5 \%$ \\
\hline
\end{tabular}

graph

Out of the 40 patients who were operated for resection and anastomoses of Bowel, 30 patients (75\%) were operated on an emergency basis and remaining 10 patients $(25 \%)$ were operated on an elective basis with preoperative bowel preparation and correction of nutritional status and haemopoitic deficiencies if present.

\begin{tabular}{|c|c|c|}
\hline $\begin{array}{l}\text { Resection \& anasto- } \\
\text { moses }\end{array}$ & Number & $\begin{array}{l}\text { Percentage } \\
(\%)\end{array}$ \\
\hline emergency basis & 30 & 75 \\
\hline Elective & 10 & 25 \\
\hline
\end{tabular}

Remarkably none of the prepared elective resection anastomoses leaked and thus the leaks observed in this series were only in the emergency laparotomy group. Out of the 30 patients who underwent emergency surgery $10(33.3 \%)$ patients developed postoperative anastomotic leaks.

Table 10: Surgeries and leaks

\begin{tabular}{|lll|}
\hline Surgery & Number of leaks & $\begin{array}{l}\text { Percentage } \\
(\%)\end{array}$ \\
\hline Emergeny (30) & 10 & 33.3 \\
\hline Elective(10) & 00 & 00 \\
\hline
\end{tabular}

For convenience of the study the resections done have been divided as follows:

- Isolated Small bowel Anastomoses

- Isolated Large bowel Anastomoses

- Anastomoses between Small and Large bowel.

\section{Small bowel Anastomoses}

Includes Jejunal Resection Anastomoses, Ileal Resection and Anastomoses and Jejuno-Ileal Anastomoses.

Total number of patients who underwent anastomoses in the Small bowel was 18 (45\%).
Among which Jejunal Anastomoses were 3 (16.6\%), Ileal Anastomoses were $13(72.2 \%)$ and the Jejunoileal Anastomoses were 2 (11.1\%).

\section{Large bowel anastomoses}

Includes patient undergoing left hemicolectomy, left anterior resection and End to End Anastomosis, segmental resection and End to End Anastomosis.

\begin{tabular}{lll}
\hline Table 11: Small Bowel Anastomoses $(\mathrm{N}=18)$ & \\
\hline $\begin{array}{l}\text { Small Bowel Anasto- } \\
\text { moses type }\end{array}$ & Number & \multicolumn{1}{c}{ Percentage } \\
$\begin{array}{l}\text { Jejunal Anastomoses } \\
\text { Ileal Anastomoses }\end{array}$ & 3 & $16.6 \%$ \\
$\begin{array}{l}\text { Jejunoileal Anasto- } \\
\text { moses }\end{array}$ & 2 & $72.2 \%$ \\
\hline
\end{tabular}

Total number of patients who underwent anastomoses for large bowel were $6(15 \%)$, amongst which left hemicolectomy were $1(16.6 \%)$,anterior resection with End to End Anastomosis were $2(33.3 \%)$ and segmental resection and anastomoses were $3(50 \%)$

\section{Anastomoses between Small and Large Bowel}

Includes patients who underwent Right hemicolectomy, Duodeno descending colon anastomosis, segmental resection with end to end anastomosis, ileal resection with End to End ileal and ileo-transverse Side-to Side anastomosis.

Total number of patients who underwent anastomoses between small and large bowel were $16(40 \%)$. Amongst wh ch right hemicolectomy were $8(50 \%)$, segmental resection with End to End anastomoses were 5 (31.2\%),segmental resection with End to End and Ileo-transverse Side to Side anastomosis were $2(12.5 \%)$, duodeno-desecending colon End to End anastomosis were 1 (6.25\%). Total number of patients who underwent anastomoses for large bowel were $6(15 \%)$, amongst which left hemicolectomy were 1 (16.6\%),anterior resection with End to End Anastomosis were 2 (33.3\%) and segmental resection and anastomoses were $3(50 \%)$

\section{Anastomoses between Small and Large Bowel}

Includes patients who underwent Right hemicolectomy, Duodeno descending colon anastomosis, segmental resection with end to end anastomosis, ileal resection with End to End ileal and ileo-transverse Side-to Side anastomosis.

Total number of patients who underwent anastomoses between small and large bowel were $16(40 \%)$. Amongst wh ch right hemicolectomy were $8(50 \%)$, segmental resection with End to End anastomoses were 5 (31.2\%),segmental resection with End to End and Ileo-transverse Side to Side anastomosis were $2(12.5 \%)$, duodeno-desecending colon End to End anastomosis were $1(6.25 \%)$. 
Among the 18 patients who underwent small bowel anastomoses $4(22.2 \%)$ anastomoses leaked.

Among the 6 patients who underwent large bowel anastomosis $2(33.3 \%)$ Anastomosis leaked.

Among the 16 patients who underwent anastomosis between small andlarge bowel 2 (12.5\%) anastomoses leaked

\section{Risk Factors}

In the present study out of 40 patients $30(75 \%)$ had either single or multiple risk factors and $10(20 \%)$ had no risk factors. The risk factors observed have been categorized in the following chart.

\begin{tabular}{|llll|}
\hline \multicolumn{2}{|l|}{ Table 12: Risk factors } & & \\
\hline $\begin{array}{l}\text { S. } \\
\text { No. }\end{array}$ & Risk Factors & $\begin{array}{l}\text { Patients } \\
\text { N=40 }\end{array}$ & $\begin{array}{c}\text { Percentage } \\
(\%)\end{array}$ \\
\hline 1 & Anaemia & 11 & $27.5 \%$ \\
\hline 2 & Hypoproteinaemia & 9 & $22.5 \%$ \\
\hline 3 & Peritonitis & 8 & $20 \%$ \\
\hline 4 & Septicemia & 3 & $7.5 \%$ \\
\hline 5 & Uraemia & 4 & $10 \%$ \\
\hline 6 & Old age & 5 & $12.5 \%$ \\
\hline
\end{tabular}

\section{Techniques Used for Anastomoses}

Small bowel Anastomoses: Out of the 18 cases of small bowel anastomoses $15(83.3 \%)$ were done in Two layers and 3 cases were anastomosed by Single layer continuous sutures.

Amongst the 15 cases anastomosed by Two layers, 10 $(66.6 \%)$ cases were anastomosed by outer interrupted and inner continuous fashion out of which $1(6.6 \%)$ anastomosis leaked. $2(13.3 \%)$ cases were anastomosed by both layers in continuous fashion out of which $2(66.6 \%)$ anastomoses leaked. $1(10 \%)$ cases were anastomosed by both layers in interrupted fashion out of which both cases (100\%) leaked.

Out of the 3 cases anastomosed by single layer continuous sutures none of the cases leaked.

Large bowel anastomoses: out of the 7 cases of large bowel anastomoses $5(71.42 \%)$ cases were anastomosed in Two layers and $2(28.57 \%)$ cases were anastomosed by single layer interrupted sutures.

Out of the 5 anastomoses done in Two layers, 3 (60\%) were anastomosed by outer interrupted and inner continuous sutures and none of the cases leaked. 1 (20\%) case was anastomosed by both layers in continuous fashion and itdidn't leak. $1(20 \%)$ case was anastomosed by both layers interrupted fashion and the anastomoses leaked.

Out of the 2 anastomoses done in Single layer interrupted suture, $1(50 \%)$ case leaked.
Small and Large bowel anastomoses: Out of the 16 cases of anastomoses between small and large bowel all were anastomosed in Two layers.

Amongst the 16 cases anastomosed by Two layers, 10 $(62.5 \%)$ cases were anastomosed by outer interrupted and inner continuous fashion out of which $2(20 \%)$ anastomosis leaked. $1(10 \%)$ cases were anastomosed by both layers in continuous fashion none of the cases leaked. 2 (20\%) cases were anastomosed by both layers in interrupted fashion out of which $1(20 \%)$ case leaked.

\section{Mortality}

Total in patient mortality was $4(8 \%)$. Total anastomotic leaks being $11(27.5 \%)$, out of which $4(36.6 \%)$ patients recovered after relaparotomy and no complications were observed, 4 $(36.6 \%)$ patients were managed conservatively. Thus mortality in leak group was $3(75 \%)$.

Mortality in non leak group was $1(25 \%)$, cause of death in this patient was myocardial ischaemia and she was a known case of ischaemic heart disease with type 2 diabetes mellitus.

\section{Discussion}

Most operations on the gastrointestinal tract involve the suture or anastomoses of the gut, and it is this aspect of the alimentary canal that is associated with dangerous complications. The breakdown of the suture line of anastomoses can result in fecal fistulation and serious or fatal septic complications. Operations on the intestines are very common surgical procedures being done by the surgeons. These operations requiring resections and anastomoses of the bowel account for roughly $20 \%$ of all the laparotomies being done in our institution. ${ }^{[7-10]}$

Even though resection and anastomoses of the intestines is a common surgical procedure it is still at times associated with morbidity in the form of anastomotic leak, stricture formation, fecal fistula and diverticulum and at times Mortality due to the associated septic complications. Morbidity in patients is not only a loss to the patient but to the society in which the patient is a part. Anastomotic leaks result in dramatic increase in hospital stay and as such the management is an expensive affair to the patient and in a majority of cases operated in a Government Hospital to the nation.

The present study showed the maximum incidence of resection anastomoses was between patients in the age range of 31 to 45 years $(37.5 \%)$ and the next group was those above 61 years $(25 \%)$. These years in a mans life are considered the most important in terms of materialistic gains which only emphasizes the loss in terms of morbidity and mortality to the individual and the society in which the individual is a part.

\section{Causes for the resection}


In this study there were various causes for the resection of the intestine. The majority of patients i.e, $16(36 \%)$ had undergone resection of the intestine for Intestinal Obstruction for a mechanical cause. Of the 16 cases of intestinal obstruction operated in Emergency setting post operative adhesions (37.5\%) and intussusception (12.5\%) were the most common causes followed by strictures, bands, volvulus and ileal knots. Abdominal Koch's (3 patients)also being the common cause in India.

The second common cause for undergoing resection of the intestine was malignancy 10 cases (25\%). All these 10 patients were operated after adequate staging of the disease radiologically and concluding that these tumours were operable.

The next group was those who had irreducible obstructed hernia (4 patients and 10\%). Of these patients who had Inguinal Hernia and presented to us with obstruction and gangrenous part of the bowel requiring resection and anastomoses were $2(50 \%)$. The patients who needed resections with adherent intestines for the repair of recurrent Incisional Hernia were 2 $(50 \%)$.

\section{Anatomical Divisions of the resections}

In the present study all the patients who underwent resections were divided into the following groups:

\section{Isolated Small Bowel Anastomoses.}

\section{Isolated Large Bowel Anastomoses.}

\section{Anastomoses between Small and Large Bowel.}

Among these 3 groups the maximum patients were in the small bowel group accounting for 18 patients and $45 \%$ of the total patients, then it was the small to large bowel group accounting for 16 patients and $40 \%$ of patients and the last group i.e., the isolated large bowel group accounted for 7 patients and $17.5 \%$.

Among the small bowel resections, Ileal resections were the majority accounting to 13 patients and $72.2 \%$ of all small bowel resections. In 3 patients (16.6\%) Jejunal resection and anastomosis was carried out. Jejunoileal resection and anastomosis was done in 2 patients (11.1\%).

Among the anastomoses done between the large and small bowel Right Hemicolectomy was the most common procedure that was done accounting for 8 patients and $50 \%$. Next were segmental Colonic resections 5 patients and $31.2 \% .2$ patients i.e., $12.5 \%$ underwent a side to side ileo-transverse bypass following segmental resection and End to End Anastomoses. $1(6.25 \%)$ underwent extensive resection of small and large bowel and a duodeno descending colon anastomoses was done.

Amongst the isolated large bowel group left anterior resection was done in 2 patients (33.3) and right segmental resections were done in 3 patients each accounting for $50 \%$ each and followed by 1 (16.6\%) case of left hemicolectomy.

\section{Anastomotic Dehiscence and Leaks}

A total of 8 patients $(20 \%)$ developed postoperative leaks among which4 patients recovered with a relaparotomy and 4 patients recovered by conservative and supportive management. Western Literature quote variable rates of leaks ranging from $2.0 \%$ to $6 \%{ }^{[11,12]}$ Much higher rates of leak i.e., around $20-25 \%$ have been reported in literature in patients undergoing low colonic resections and in series in which patients undergo routine radiological evaluations of anastomoses postoperatively.

\section{Correlation of Leak with Risk Factors}

- 7 of the 11 patients who developed leak postoperatively had serum Albumin levels less than $3.0 \mathrm{~g} / \mathrm{L}$.

- 3 of these patients had postoperative Albumin Infusion, the remaining 4 patients were also advised the same but could not do so because of the cost involved in the treatment.

- 9 patients (22.5\%) of the patients in this series had hypoproteinaemia however only 7 patients with hypoproteinaemia developed leak, the remaining 2 patients were treated both pre and postoperatively aggressively with Albumin and Blood transfusions.

- 11 patients (27.5\%) had anaemia of hemoglobin less than $8 \mathrm{gm} \%$, among which a majority of them were females. However only 7 patients developed leaks and preoperative transfusion of packed cells was advocated only in 4 patients among which all the 7 were a part.

- As a majority of these anaemic patients did not develop leak its significance in anastomotic healing is doubted.

- Bacterial peritonitis was observed in 8 patients $(20 \%)$ out of which 7 developed postoperative anastomotic leaks.

- In all the 11 patients who had leak there was preoperative Hypovolaemia-shock.

- 7 of the 11 leak patients had also received preoperative transfusion of 2 units of packed cells.

- 12 patients in the study group had Chronic Obstructive Pulmonary Disease (COPD) out which all the patients who leaked were a part expect one in the pediatric age group.

- Out of the 11 patients who leaked 3 of them were above 61 years and remaining of them were below 60 years. Thus old age was an indicator of leak.

\section{Mortality and Morbidity}

The total inpatient mortality observed in this study was 3 patients $(7.5 \%)$. A total of 10 patients developed anastomotic leak out of which 4 patients survived after a relaparotomy and 2 patients recovered by conservative management. However the remaining 3 patients died had anastomotic leak related septic complications accounting for $75 \%$ of the overall mortality. The other $1(10 \%)$ patient who died was in the non leak group and 
was a known diabetic and ischaemic heart disease patient and died due to Myocardial infarction.

Among the patients who died 3 (75\%) had leaked and thus anastomotic leak was itself a significant predictor of mortality in this study.

\section{Conclusion}

Large bowel anastomoses with interrupted sutures has higher rate of leak and no difference in the rate of anastomotic leak with the different technique used in the anastomoses between small bowel and between small and large bowel. Adequate blood supply to the two cut mucosal edges is essential. Ends should be sutured without undue tension. Irrespective of the suture material used the anastomoses will heal. The preferred suture material was Vicryl were affordability was not a factor. Anastomotic leaks were an independent predictor of mortality. No effect of gender and Obesity. Anastomotic leaks were more in the elderly individuals There is no effect of Diabetes on the anastomotic healing.

\section{Acknowledgment}

The author thankful to Department of Surgery, Kamineni Institute of Medical Sciences for providing all the facilities to carry out this work.

\section{References}

1. Hautefeuille P. Gastrointestinal suturing: Apropos of 570 sutures performed over a 5 -year period using a single layer continuous technique. Chirurgie. 1976;102(2):153-65.

2. Burch JM, Franciose RJ, Moore EE, Biffl WL, Offner PJ. Single-Layer Continuous Versus Two-Layer Interrupted Intestinal Anastomosis. Ann Surg. 2000;231(6):832837. Available from: https://dx.doi.org/10.1097/00000658200006000-00007.

3. Garude K, Tandel C, Rao S, Shah NJ. Single Layered Intestinal Anastomosis: A Safe and Economic Technique. Indian J Surg. 2013;75(4):290-293. Available from: https://dx.doi.org/10. 1007/s12262-012-0487-7.

4. Khan R, Hameed F, Ahmed B, Dilawaiz M, Akram M. Intestinal anastomosis: comparative evaluation for safety, cost effectiveness, morbidity and complication of single versus double layer. Professional Med J. 2010;17(2):232-266.

5. Max E, Sweeney WB, Bailey HR, Oommen SC, Butts $\mathrm{DR}$, Smith KW, et al. Results of 1,000 single-layer continuous polypropylene intestinal anastomoses. Am J Surg. 1991;162(5):461-467. Available from: https://dx.doi.org/10. 1016/0002-9610(91)90262-c.

6. Hyman N, Manchester TL, Osler T, Burns B, Cataldo PA. Anastomotic Leaks After Intestinal Anastomosis. Ann Surg. 2007;245(2):254-258. Available from: https://dx.doi.org/10. 1097/01.sla.0000225083.27182.85.

7. Ceraldi CM, Rypins EB, Monahan M, Chang B, Sarfeh IJ. Comparison of continuous single layer polypropylene anastomosis with double layer and stapled anastomoses in elective colon resections. Am J Surg. 1993;59(3):168-71.

8. Leslie A, Steele RJC. The interrupted serosubmucosal anastomosis - still the gold standard. Colorectal Dis. 2003;5(4):362-366. Available from: https://dx.doi.org/10 1046/j.1463-1318.2003.00460.x.

9. Askarpour S, Sarmast M, Peyvasteh M, Gholizadeh B. Comparision of single and double layer intestinal anastomosis in Ahwaz educational hospitals. Internet J Surg. 2005;23(2):45-54.

10. Waard D. Retinol may promote fluorouracil suppressed healing of experimental intestinal anastomoses. Arch Surg;130:19952004.

11. Katz S. Bacterial adherence to surgical sutures. A possible factor in suture induces infection. Ann Surg. 1981;194:35-35.

12. Murphy JB. Cholecyst-intestinal, Gastro-intestinal, Enterointestinal anastomosis, and approximation without sutures. Med Rec. 2017;42:665-71.

Copyright: (C) the author(s), 2020. It is an open-access article distributed under the terms of the Creative Commons Attribution License (CC BY 4.0), which permits authors to retain ownership of the copyright for their content, and allow anyone to download, reuse, reprint, modify, distribute and/or copy the content as long as the original authors and source are cited.

How to cite this article: RR. A Clinical Study - Resection and Anastomosis of Bowel in Our Surgical Practice. Acad. J Surg. 2020;3(1):1-7.

DOI: dx.doi.org/10.47008/ajs/2020.3.1.1

Source of Support: Nil, Conflict of Interest: None declared. 